\title{
Academic Teacher Induction in a Multiple Campus University Environment 2 - Engagement in Professional Development
}

\author{
Marie B. Fisher, Anna Gemmell \\ Australian Catholic University, Australia
}

\begin{abstract}
Significant changes occurring in the Higher education sector in Australia since 2009 regarding academic teaching standards, pressure to publish, maintaining currency with technology and achieving secure employment appear to affect the inclination of new academics to participate in short term professional development. 'Just in time' or staged approaches that address a pathway to build learning and teaching experience during a semester would be more viable as it supports staff in their new academic role while at the same time addressing barriers facing new academics. It is hoped that by sharing our experience at the Australian Catholic University (ACU) and seeking feedback from the global community, we can create opportunities to integrate this staged approach to complement face to face workshops and provide improved support for our new academic teachers by helping them develop their sense of identity in their new teaching roles.
\end{abstract}

\section{Introduction}

The aim of this paper is to outline the challenges that affect design, development and delivery of Academic teaching induction in face to face workshops to support new academics in a multiple campus university environment. Also, it is important to acknowledge that part of this journey is also about building resilience in new academics so they are more inclined to participate in professional development that will help them ease into their new teaching role and encourage them to be self-directed in their ongoing career development.

We wish to share our observations and reflect upon this how we are supporting new academic teachers as well as communicate the strategies we used to overcome these obstacles at ACU. Challenges for new academics may include commencing in their new role late as their employment for sessional staff particularly, is usually linked with the number of students enrolled in a unit of study or degree program. If there are last minute increases in undergraduate student numbers at ACU due to late offers of a place in a degree program, there is a need for additional teaching staff to be engaged by faculties. Therefore, participation in any form of professional development places additional stress or pressure on these teachers to develop units of study they are teaching in much

shorter time frames, sometimes after classes have commenced.

Availability of workshops offered on their campus may be difficult to communicate with them via normal means because they have such a short lead in time. Informal feedback from attendees and observation from more experienced academics during 2016 and early 2017 indicate that a 'one off' Introduction to Learning and Teaching workshop delivered across multiple campuses at ACU is not fulfilling the needs of academics new to our University.

'Just in time' or staged approaches that address a pathway to build learning and teaching experience during a semester would be more viable as it supports staff in their new academic role. Professional development has been offered as a single activity rather than a program or journey the academic new to ACU embarks upon [12].

It is hoped that by documenting and sharing our experience and seeking feedback from the global community we can help colleagues in similar situations worldwide address this issue. At the same time, we expect to be able to provide improved support for our new teachers at ACU by developing variety of sustainable strategies to offer timely, useful support.

\section{Literature Review}

The literature review did show that there had been some studies in recent years explaining why academic staff may resist 'voluntary' professional development and best practices adopted by institutions to support learning and teaching initiatives for academics new to their institutions. The results were not surprising.

In Australia, since 2009 [1] there has been pressure from government and accreditation bodies on universities to improve student outcomes and provide excellent learning and teaching experiences for them in their undergraduate and postgraduate courses. Addressing the diverse needs of students from non-traditional cohorts who may have literacy challenges has been a concern for Australian universities [2]. This means that there is an expectation that academics new to teaching will engage in academic induction introducing them to 
learning and teaching frameworks expected to be integrated into their respective disciplines [1], [3].

Many academics struggle to develop a professional identity for several reasons. Issues with workload, diversity of duties and projects such as: research, scholarship, keeping up to date with their discipline, student management and administration as well as the additional requirement of integrating a Teaching Framework put pressure on academics [4], [5]. If a staff member is time poor then it is likely to mean that professional development, if optional, is not always viewed as important compared to meeting targets particularly if financial support to attend is not offered.

In 2013 an Australian Government Office for Learning and Teaching fellowship was granted to a group of Australian universities to develop a benchmarking activity for sessional (casual) academic staff called 'BLASST - Benchmarking Leadership and Advancement of Standards for Sessional Teaching' [6], [7]. This project investigated how sessional (casual) academic teaching staff were supported in their role and the challenges they faced with regard to ongoing professional development [6], [7].

Through this investigation the project group highlighted three guiding principles that underpin the Sessional Staff Standards Framework namely: Quality Learning and Teaching, Sessional staff support and Sustainability. Each principle contained different standards of achievement against criteria such as: "1.1a The institution articulates the employment and educational skills required from a sessional staff member [6].

If a university demonstrates good practice then they provide a clear statement of skills, qualifications, experience and expectations that is included in the Enterprise Agreement and reflected in policies and procedures [5]. Whereas if minimum standards are achieved by a university they may only specify minimum qualifications required for teaching undergraduate courses eg a Bachelor's degree.

However when an institution does not clearly articulate the minimum skills or qualifications required by sessional staff or articulates requirements on an ad hoc, informal basis which may be variable across the university then the quality of learning and teaching is unsustainable [6].

An important point to note in the Higher Education Standards Framwork, 2015 that sessional or casual academics are less likely to complain or express concern publically about their lack of training as they are probably looking for more permanent employment and if they are perceived to be 'high maintenance' and always asking for help then this opportunity may not be offered even if they cope with the demands on them [9].

Recent research has supported our observations and reflection over the last three years indicating that resistance to academic development or induction occurs for several reasons such as:

The relevance of professional development 'what's in it for me' may not be obvious to the new sessional academic as they don't have enough engagement with the university to recognise the nexus between their teaching practice and a career development plan [4], [5].

Disciplinary: knowledge of their discipline is more important than academic induction or integration of teaching frameworks.

Student deficit: perception by some academics that students admitted to university are less academically capable due to poor schooling.

Skill and performability: perceptions by academics that skills of a good teacher may be limited to excellent public speaking or performing rather than integrating a teaching framework and engaging with the complexity of $21^{\text {st }}$ century teaching necessary for excellence in teaching one's discipline [8], [10], [11].

At the same time the perceived relevance of professional development by some academics may be linked to attaining formal qualifications such as a doctorate. Some staff who would be more inclined to participate may also recognise the benefits such as earning a Graduate certificate in Higher Education, or some other credential that integrates technology with pedagogy [2], [4], [10 ].

If these credentials lead to advancement in their career or an opportunity for more permanent employment, they would be more inclined to engage. While the benefits of involvement in a staged career plan that aligned to both their needs and teaching excellence in the Higher education milieu would provide incentive for them to become more selfdirected in their professional development [4], [12].

\section{Background}

At ACU a Professional Development continuum has been designed and developed over the last eighteen months in consultation with faculties and through the experience of other Higher Education institutions [13], 14].

Academics from other higher education institutions frequently report that the Introduction to Teaching program (ILAT) doesn't offer them anything they don't already know. The content and structure of this program at ACU focus on those first vital steps in one's new role to becoming a successful teacher and collaborating with others (within and across faculties) and transforming their teaching through community and sharing experiences [14].

The 'Introduction to Learning and Teaching' (ILAT) face to face workshop program, offered once per semester on all domestic campuses, has been designed as the first step in orientation to teaching at the Australian Catholic University. The workshop 
program introduces teaching focused academics, new to our university, to the governance, structures, organisation, policies and procedures that underpin new academic teachers' learning and teaching activities. An overview of additional academic development initiatives which are available to them to foster excellence in teaching are also covered [5], [14]. Attendance at a workshop on one's local campus is highly recommended but not compulsory at our institution. According to the 'Professional Development for Academic staff policy', responsibility for engaging in one's development rests with the academic staff member and is not mandatory but encouraged [15].

These development initiatives are included under the 'umbrella' 'Teacher Professional development continuum program' within the Learning and Teaching Framework 2014-2017' designed to transform the future direction of learning and teaching at our University [5].

While face to face workshops have been considered, by attendees, to be useful to academic teachers new to ACU supported by an increase of 78 percent increase in participation at our University over the last two years, feedback and observation by the authors and recent research, has indicated that they want to be able to access operational and pedagogical help, as they develop and mature in their role and seek improved approaches to engaging their students while at the same time fulfilling their administrative responsibilities [13].

Therefore, assistance provided at different stages of the semester when they need it most or 'just in time', either with a group of experienced colleagues on their campus or in a community engagement style of session could be helpful. Engagement with colleagues via webinar across campuses has also been suggested by new academics to address issues arising in the first four to six weeks of teaching in a collaborative environment [11], [16]. It is evident from observations and informal feedback that new academic teachers are not sure what support they need when they commence at the university and attend the face to face workshops [17].

The support they need emerges through experience gained from teaching activities such as marking and providing feedback on the first assessment piece in week 3 or engaging with students about certain issues online at particular points in the semester or teaching period. While at the same time they need to demonstrate working effectively with colleagues on curriculum development and other collaborative initiatives outlined in both teaching and human resource management frameworks at ACU [5], [17], [18].

\subsection{The Australian Higher Education Context}

The Australian Higher Education sector continued to undergo significant changes aimed at improving student outcomes and consistency in provision of Education services in 2016. The Higher Education Standards Framework (Threshold Standards) was established under the Tertiary Education Quality and Standards Agency Act 2011 (TEQSA Act 2011) was published in 2015. These standards set out the minimum acceptable requirements for higher education providers to improve student outcomes and learning experiences that should link to future work environments [9].

Implementation of change management legislation and direction in the sector has highlighted excellence in learning and teaching as a key priority not just at our university but at other higher education institutions [10], [13], [15]. Significant challenges integrating technology into learning and teaching activities are due in part to: differing levels of digital literacy across the sector for both academic teachers and students; balancing our connected and unconnected lives and ensuring education is relevant to current and future employment opportunities not just for students but academics as well [1], [2], [10].

\section{Australian Catholic University}

Australian Catholic University (ACU) was established in 1991 and formed from an amalgamation of teaching colleges, and religious institutes in Eastern Australia. There are 7 domestic campuses in 4 states, New South Wales (NSW), Queensland (QLD), Victoria (VIC), South Australia (SA), and 1 territory, Australian Capital Territory (ACT) [4]. An additional international campus, a joint venture with the Catholic University of America, was opened in Rome in September 2015. The University emerged from the smaller teaching colleges established by clergy from several Catholic religious orders.

The larger campuses are situated in major cities located in Sydney, Melbourne and Brisbane. These campuses are managed by three Associate Vice Chancellors. Ballarat and Canberra campuses are led by a Campus Dean. Most campuses teach undergraduate and postgraduate courses in the four faculties: Education \& Arts, Health Sciences, Law \& Business, and Theology \& Philosophy. Each State or Territory has their own legislation and requirements for professions in Law \& Business, Education, Nursing, Paramedicine, Psychology, Physiotherapy and Social Work making the issue of uniformity and offering 'just in time' help with introduction to teaching workshops for new teachers problematic [4]. 


\section{Current Opportunities v Challenges}

Digital literacy continues to be a challenge for many academics due in part to rapid development of new and emerging technologies [2]. The issues for the senior executive of our University encompass one off, recurrent costs and the dilemma of choosing a 'one size fits all' approach that is valid for at least 3 years, to professional development support, particularly in relation to teaching focused academics who may be reluctant to engage as it may indicate they are 'not up to the job' and risking job security [11], [1].

When encouraged to enrol for a professional development offering new staff often feel overwhelmed and report that they are too busy to undertake additional training. They may appear reluctant to participate in professional development, particularly self-paced offerings. This is not uncommon based on recent academic literature on this topic [11], [1], [4].

The authors sought and accommodated feedback at the LICE Conference 2016 in the United Kingdom and considered other methods for improving the face to face experience. Provision of a more staged approach to support new academics during the teaching period was posed. In this model, communication technology could be used to host a virtual' classroom' across campuses and be facilitated from one geographic location and enable some peer review of teaching [8]. International colleagues suggested that it could be a cost effective 'just in time' strategy, that could be adopted if the technology was robust and the experience was valued by colleagues. In addition, the executive could also be convinced of the value as this approach had potential for capacity building in teaching and collaboration across campuses.

\section{Change Management}

In 2015 a review of the workshop learning outcomes and content revealed that there were too many expected learning outcomes for a half day workshop, some of which were only able to be achieved in a general rather than a specific academic teaching context. Changing the learning outcomes so that they are more targeted to academic teaching roles at that time was problematic as the primary author is the only member of the senior academic leadership team who has had recent faculty teaching experience and knowledge of their roles. Academic developers often find themselves positioned between senior management and academic staff. This situation can mean that their role unclear when required to facilitate workshops or provide support resources for new teachers [5], [16], [18].

Eliciting useful feedback from faculty staff with teaching experience, and identifying what new teaching academics needed to know, was a challenge that turned into an opportunity for continuous improvement of new teacher support [8]. This was due mainly to diverse cultures across campuses and variation in student numbers, influencing the type of teaching approaches required for large and small classes, management of units, and curriculum development, particularly on large campuses [11]. In addition, there is a wide variety of roles, responsibilities and teaching experience within disciplines revealed during workshops which has helped the National co-ordinator better understand the faculty needs of new teachers and improve the workshop content and format.

Over the last three years there has been a significant loss of corporate, university knowledge and implementation of change management in faculties and in administration at ACU. This has affected how the Learning and Teaching Centre is permitted to market workshops, liaise with faculties and support teaching focused academics.

Gauging how much technology should be used in learning and teaching activities has raised significant debate in the sector. Integration of technology is not in itself a guarantee of success for the improvement of academic capabilities, capacity building or improving student employment outcomes [1], [12]. Issues such as the type of professional development support integrating learning has been problematic with academics expressing preferences for face to face or similar labour and resource intensive development offerings which in the 21 st century university environment is not viable [10], [1].

There are many academics keen to learn and who are eager to improve their teaching. However, sometimes their enthusiasm can diminish and be linked to a lack of opportunity, support or vision when occupying casual and limited contract roles [17]. These experiences may limit their teaching growth and the 'domino effect' is that it impacts on the experience of the students. Increasing workloads due in part to the changes occurring in academic work more quickly than staff can upskill to the latest labour saving technologies are just one dilemma affecting both staff and university executives [13]. However, an opportunity to improve access, engagement and capability from the Executive through to the teaching staff has presented itself through policy changes.

The introduction and integration of the Capability Development Framework (CDF) which outlines essential competencies required for all ACU staff both academic and professional streams will be transitioning from the top down from mid-2017. The potential for this Framework to encourage all staff to participate actively and often in their own professional development while at the same time building relationships with others, is significant and important in the pursuit of excellence in teaching agenda in the Higher education sector in Australia [19]. 


\subsection{Communication to Staff Strategy}

Organisational culture in Higher Education institutions is more complicated due to differing academic priorities, administration needs as well as a perception that no one has complete authority, particularly in relation to academic development [9]. Our University is no exception and communication strategies are more problematic as they are applied across multiple campuses.

Prior to late 2014, when a new service focused Change Management approach was introduced to dispense with unnecessary duplication of services on each campus, the National Co-ordinator of ILAT was required to contact all the Associate Deans Learning and Teaching (ADLTs) in each faculty, administrators in each school by faculty and, if known, new academic staff to advise them of the workshops. This process was unsustainable given there was only one person situated on a small campus, designing, developing and delivering multiple workshops on each domestic campus at ACU.

The ILAT program is still not mandatory for new staff. Responsibility for design, development and delivery of this program rests with the Learning and Teaching Centre (LTC) although partnerships and consultation occurs between most faculties and directorates [14]. Where possible this program is integrated into school specific orientation for new academics upon request.

The success of this program each semester is somewhat dependent on administrative staff informing new staff of this option [17]. ILAT attendance and participation is input by an administrative member of the LTC into Staff Connect. Staff Connect is a Human Resources database with a section for recording professional development for academics and professional staff by organisational area at ACU.

The Staff Bulletin dispatched by Marketing via ACU staff email twice a week details training and other development opportunities. As previously mentioned, there are several other self-paced resources and offerings to support new teachers e.g. Learning Management (LEO), E-learning guides, TOC (teaching online course) and the Learning and Teaching website, as well as faculties creating their own LEO units to assist new staff [ 1], [14]. So, a pathway is important for them to know where to focus their energy and time.

While potentially this is an excellent way of streamlining communication across multiple campuses at ACU, dispensing with the need for 'email bombing' all staff, as well as removing unnecessary administration for the National coordinator, the primary author, it has resulted in the target audience, academics new to ACU and their supervisors often 'missing' the advertisement. Many academics have stated they want a more personalised approach e.g. it is included in their offer of employment (although if it is not made mandatory staff may not participate). Participation may be difficult to communicate with them via normal means because they have such a short lead in time prior to commencement at our institution.

\subsection{Staged Academic Induction Support Program}

Based on feedback from face to face ILAT workshop attendees over the last three years and our colleagues at LICE Education UK, the authors also proposed a case for a 'staged support' program for new academic teachers in their first semester of teaching at ACU, delivered by webinar. It is expected that participation in this program could be used as evidence for one or more of the recently approved ACU frameworks namely the Teaching criteria and standards framework as well as an introduction to Peer review [5], [8]. This Framework was developed in consultation and accommodation of feedback from academics in face to face workshops held on every domestic campus across ACU in 2015 and contains standards expected at each academic employment level and suggested forms of evidence which staff are expected to profile in a Teaching Portfolio [5], [8].

It is aligned to teaching only academics commencing at Level A (beginning academic) to Level D (senior academic at the Associate Professor or above level). This framework provides 7 clear, objective and consistent teaching criteria as follows:

a) Design and planning of learning activities;

b) Teaching and supporting student learning;

c) Assessment and giving feedback to students on their learning;

d) Developing effective learning environments, student support and guidance;

e) Integration of scholarship, research and professional activities with teaching and in support of student learning;

f) Professional and personal effectiveness [5].

At the time of writing this article, the proposal for the 'Staged Webinars, expected to be part of the teaching continuum, 'Just in time' program of targeted support for academic teachers new to ACU, was being considered as an extension of the face to face ILAT offerings by the Executive [8], [14].

Development, design and reflection evidence needs to be collected in an ePortfolio and used to tell a story (and profile a learning journey) [4]. These reflections upon evidence need to show how a person has improved as well as transformed challenges into opportunities to inform and adopt new approaches against Teaching Criteria [4], [5]. As the academic acquires more experience across their employment level they should be able to write reflections to show 
deeper learning and academic competence demonstrated in a Teaching portfolio.

\subsection{Self-Guided ILAT Induction Support}

Feedback from a variety of sources, since our previous conference article was published, across our University and from the LICE Education 2016 community raised some concerns about the capacity for the Learning and Teaching organisational unit at ACU to deliver the 'staged approach' to ILAT during a teaching period with faculties who may be too busy teaching to engage with new colleagues in webinars or online 'live' classrooms or know which new academics are able to participate [17], [20].

This resulted in a complete 'rethink' about the type of online offering need to offer to new staff, who may or may not have commenced work, where they could orient themselves into the uniqueness of a multiple campus environment like ACU, their new academic teaching role, find resources, support for their teaching and a professional development pathway [1], [3], [4].

It was suggested that if an online ILAT offering was available in the ACU Learning and teaching public website domain, more staff would be able to access support to help them orientate themselves into their new role prior to commencement. [6] After consultation and a briefing with the Director of the Learning and Teaching Centre, a web based online offering was developed for testing by stakeholders.

In July 2017 The Introduction to Learning and Teaching for academics new to ACU (ILAT) program consists of face to face workshops offered on all domestic campuses each semester in student orientation week and supplemented by 'in school' orientation provided by faculties [5], [6], [10].

In addition, face to face and online training to orientate staff to the technology enhanced learning milieu and become familiar with appropriate elearning tools is also provided by e-learning (nonacademic staff). 'LEO' Basics introduces new staff to the online learning and teaching environment (the LMS or learning management system called LEO at ACU). Unit outlines, resources and learning activities for their undergraduate or postgraduate students must be uploaded into a unit of study site in the LMS. Each academic creates a separate site for each subject they teach in a degree program [14].

A diagram of the ILAT pathway has been included to show the links between academic roles, resources used to support development of scholarly approaches to teaching as well as building and profiling evidence of best practice is encouraged at our University.

The authors have observed over the past three years, that academic teachers new to our University, employed as sessional or part-time staff members, were not always available to attend face to face Introduction to Learning and Teaching (ILAT) workshops which are part of the ILAT program [9], [10]. Consequently, new academics unable to attend this particular form of induction highlighted a gap in the service and support our organisational area: the Learning and Teaching Centre provide to faculty staff at ACU [13].

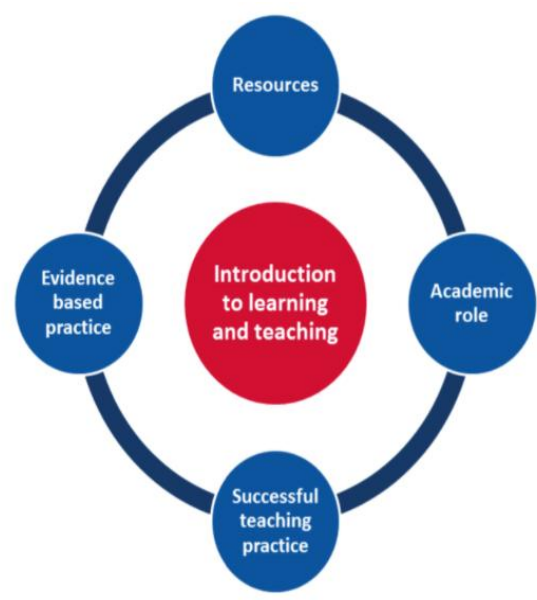

Figure 1. Introduction to learning and teaching for Academics new to ACU (ILAT)

Source: ACU Learning and Teaching website [14]

There are a number of issues that affect when these face to face workshops are offered to staff. The first consideration is that workshops are currently scheduled during Student orientation week in Semester 1 and Semester 2 on all domestic campuses to enable as many staff as possible to participate prior to commencement of teaching. As we have mentioned in our LICE 2016 conference paper, new academics are often hired by our University just prior to teaching, and in some cases when the teaching period or semester has commenced as their employment is linked to final student numbers in a particular unit of study or course [20]. So faculties need academic induction support to occur prior to or as soon as staff commence.

Considerable consultation over the last three years with academics, school administrators, senior staff in faculties, the Learning and Teaching Centre and colleagues from other universities, informed development of ILAT online academic induction support. The authors developed a number of these online professional development options for consideration to supplement or be completed by new academics in place of the face to face workshop. The first one was set up as a unit of study site in the Learning Management System (LMS) with support resources, launched in 2014, and continually revised and improved over subsequent years, relating to the content which included:

(a) A short introduction video from the Deputy Vice Chancellor, Students, Learning and Teaching Faculty; 
(b) Inclusion of a 'downloadable' e-book which included the expected learning outcomes for the introduction to teaching;

(c) Philosophy promoting respect, collaboration and sharing of teaching and research in domestic and global contexts;

(d)Assistance finding appropriate resources for student management and teaching in the professions including policies, guidelines and University rules;

(e) Details about the diverse academic roles at ACU, expectations and links to support materials;

(f) Key principles for good practice including advice about teaching strategies, curriculum design;

(g) Engagement in reflection and evidence based practice using eportfolios or teaching portfolios;

(h) Integrating learning and teaching activities into the Learning Management System named 'LEO'. It was discontinued in early 2017 due to low statistics on the website.

Academics who attended face to face workshops were allocated student-user level access with their University logon to the site. Those who did not attend the workshop were also enrolled as studentusers in the site if faculties advised the ILAT National Co-ordinator that there were other new academics that commenced after the workshops were conducted. Observation by the authors, colleagues and informal feedback from people who used the resources was positive about content, resources and the e-book. However, most academic teachers who were new to ACU perceived that they did not have time to use this online resource regularly due to their workload and senior academics at ACU who were not teaching were unsure about the value of this offering.

The authors conceded that while the unit based online resource was useful, they would need to design and develop a different type of online offering which could be accessed via the ACU Learning and Teaching website hosted in the public domain of ACU. As a result they developed a second online option in 2017. It is expected that this academic induction professional development will be launched in mid to late 2017 once all feedback on the design, development and content of this offering has been accommodated. Additional collaboration from a team academics, professional staff and educational designers is needed so that they fully understand that the brief was very general and, as a result the selfguided resource was developed as a work in progress at the request of the Director (Dean) of Learning and Teaching at ACU. The ILAT self-guided resource that will be hosted in the ACU Learning and Teaching public website is an online academic development offering developed to mirror the content disseminated in the face to face workshops, except there will be no interaction with colleagues in the online version. The aim of this resource is to enable academic teachers to prepare for their new teaching roles and access support in the ACU
Learning and Teaching public website prior to finalisation of their employment contracts.

In response to informal feedback from new academic teachers who reviewed this offering, the program was designed as a question and answer style of professional development in the form of a web based online self-guided resource thus addressing the 'what's in it for me'? [6], [10]. The program provides a dual pathway of support which academics self-select when they are considering what might be required in their new academic teaching role eg new to higher education or experience from another institution. Academics new to ACU and Higher education teaching would be able to access this offering prior to commencement in the University Learning and Teaching public website.

Despite the extraordinary increase in support and resources for new teachers, there is still a need to fill the gap to support them as they begin building their teaching strategies at ACU. At the same time, it is important for them to improve their digital literacy to build experience in learning and teaching; increase knowledge of university systems and acquire ability in a diverse range of administrative tasks to improve student engagement in the short term.

Recent findings detailed in the Horizon report just published in February 2017 indicate that universities are positioning themselves to become more competitive and relevant to students and employers by encouraging and participating in innovation [10].

Innovation may take the form of building entrepreneurial relationships with businesses to improve student to work transition and more importantly promote learning at a university as a dynamic rather than a static experience [10]. Simultaneously academics have opportunities to build collaborative working relationships, experience and develop deeper learning skills, knowledge and attributes in studies that relate to the real world, which would be more transferable to private or public sector employment milieu [10], [4], and [5].

While 'live' workshops in virtual environments are popular with some types of professional development and may engage staff who would prefer a 'staged' approach possibly delivered by webinar, there are issues with capacity building so that a team rather than one or two people can deliver at different times. A team approach where a group of people are developing or delivering high quality professional development enables capacity building among those responsible for learning and teaching support while at the same time supports our teaching academics.

Issues with capacity building, the perceived value and understanding of a professional development offering is an important set of hurdles to overcome. A key strategy for negotiating those hurdles is for the higher education sector to encourage changing academics' attitudes towards actively pursuing their own development. With encouragement, supported by clear institutional policies and procedures, more 
academics would feel confident to pursue professional development relevant to their needs such as promotion or more permanent work. Our University is already addressing these issues [12], [16], [20].

\section{Theoretical Approaches}

Engagement of attendees with their colleagues in workshops is encouraged through exploring issues arising in real life learning and teaching by working through scenarios. They are encouraged to discuss issues arising in their assigned scenario and work with colleagues in multi-school groups to develop a solution. This is 'scaffolded' by the academic development facilitator using a Scholarship of Learning and Teaching approach (SoLT) [16]. This process may involve discussions that will challenge and transform how they may be thinking, practicing and integrate experience via a learning and teaching framework amalgamated into their discipline [5]. Collaboration with colleagues and discussions about their work is a useful form of professional development based on colleagues' informal comments at ACU. Knowledge, skill building and new teaching strategies can be enhanced through listening to others discuss (or watch them in their classes) learning and teaching experiences. Sharing and providing academics with peer feedback at ACU has been experienced through the PORT Peer Observation program [8], [14].

Through collaborative learning opportunities offered to academic teachers in face to face as well as a proposed virtual learning environment it is expected that support and assistance from colleagues will be a more useful way to develop experience and capability in a university environment [4], [5], and [14]. It is more likely to provide a forum to help new academics solve issues arising from teaching experience during the semester. While it is proposed to offer the 'staged approach' in real time those staff unable to attend could benefit from reviewing the short recording of 5-10 mins when they have time available. An overview of the key points that came up during the webinar recording would also be beneficial.

Transformative learning is possible through collaboration and community of practice, which may involve meeting regularly via webinar or on their local campus, to improve practice and the value of teaching, and in this way, achieve excellence in teaching [12], [16]. Developing one's professional teaching practice is part of the Learning for Life Framework 2014-2017 an initiative designed and developed to encourage, support and reward a continuum of excellence in learning and teaching at our University [5].

\section{Conclusion}

The authors have observed through their teaching, learning and self-reflection that providing a 'one size fits all, just in time' introduction to learning and teaching support model is no easy task. It will take time to develop a flexible continuum of academic teacher induction support that serves our target audience supported by new academics that selforganise a community of practice model the share knowledge, teaching practice and ideas in a face to face or virtual environment for each campus.

At ACU, in the PD continuum, which mostly concentrates on integrating technology with pedagogy in real life teaching situations, there are several offerings that staff are encouraged to participate in after ILAT. Introduction of the Teaching Support Program (TSP) offered in the last eighteen months has enabled new staff to build more confidence in developing and designing learning activities in an online environment.

Whereas the Graduate Certificate in Higher Education (GCHE) has been reviewed and redesigned to help academics develop their career as a tertiary educator [15]. The introduction of the Peer Observation Review of Teaching (PORT) provides a framework for ongoing improvement of learning and teaching practice through peer collaboration, discussion and sharing ideas about good practice [5]. [15].

While the journey so far has been interesting as we learn more about our own preferred learning, teaching, curriculum development and professional practice, we have considerable work to do in consultation with faculties, campuses and the Executive if we wish to support new teachers' confidence and engagement in their own learning.

Improvement in communication strategies about teaching support options, available to all our academic teachers new to ACU, is helping academics change their thinking about how useful professional development is for excellent teaching.

However, to engage academics we need to help them discover and address where they have gaps in digital literacy, engage them with the ACU teaching criteria and framework that integrates with their respective discipline and encourage self-directed transformational learning through collaborating and sharing knowledge, skills and ideas with their colleagues in their own faculties as well as across ACU.

The ILAT journey is a complex one. To ensure we have dynamic high quality support for academic teachers it will require a commitment to continuous improvement from academics to transform learning [12]. 16]. We would encourage them to provide continuous feedback to inform the authors and others providing professional development about the best ways to design, develop and deliver useful options for academics new to ACU using a Scholarship of 
Learning and Teaching approach [5], [16]. In the future it is likely that there will be multiple methods to deliver online professional development support for academics including mobile applications as well as enhanced simulation computer programs. [10]

Therefore, we seek and would like to accommodate global feedback to improve our practice as well as help other universities across the world by sharing our own experiences of design, development and delivery of academic support for teachers new to ACU.

\section{References}

[1] Simon McIntyre "Reducing the digital literacy divide through disruptive innovation", HERDSA Review of Higher Education, Vol. 1, The University of New South Wales, Australia, 2014. Located at: www.herdsa.org.au (Access Date: 1 July, 2016)

[ 2] Mark T. McMahon, "Ensuring the development of Digital Literacy in higher education curricula", Edith Cowan University Research Online, Proceedings of Annual Conference of the Australasian Society for Computers in Learning in Tertiary Education (ASCILITE), New Zealand, pp.524-528.

[3] Ann Luzeckyj and Lorraine Badger, "Literature review for Preparing Academics to Teach in Higher Education (PATHE)", Australian Learning \& Teaching Council, Flinders University, Australia, 2008, pp.1-20.

[4] Marie B. Fisher, \& Andrew J Hill "Eportfolio Adoption and Implementation in a Multiple Campus University Environment 4 - Disruptive Change and Innovation", International Journal for Infonomics (IJI), Volume 8, Issue 4, London, UK, December 2015.

[5] Learning and Teaching Centre, "University-wide teaching criteria and standards framework," Australian Catholic University, December 2015. http://www.acu. edu.au/policies/807558 (Access Date: 1 July, 2016)

[6] Karina Luzia, Marina Harvey, Nicola Parker, Coralie McCormack, Natalie Brown and Jo Mackenzie, "Benchmarking with the BLASST Sessional Staff Standards Framework", Journal of University Teaching \& Learning Practice, 10 (3), Australia, 2013, pp.1-15

[7] Macquarie University, University of Canberra, University of Tasmania, University of Technology, 'BLASST: Benchmarking leadership and advancement of standards for sessional teaching' Australia, 2013. http://blasst.edu.au/docs/A413_008_BLASST_Benchmark _Guide.pdf (Access Date: 1 March, 2017).

[8] Graham D. Hendry and Gary R. Oliver, "Seeing is Believing: The Benefits of Peer Observation", Journal of University Teaching and Learning Practice, 9(1), University of Wollongong, Australia, 2012, pp.1-8.

[9] Simon Birmingham, "Higher Education Standards Framework (Threshold Standards) 2015", Federal Register of Legislation, Commonwealth of Australia, Australia, 2015, pp.1-22. https://www.legislation.gov.au/Details/
F2015L01639/ (Access Date: 1 July, 2016)

[10] NMC Horizon Report, 2017 Higher Education Edition, NM (New Media Consortium), Texas, USA, 2017, pp. 1-57. http://cdn.nmc.org/media/2017-nmc- horizonreport-he-EN.pdf (Access Date: 1 March, 2017).

[11] Lynn Quinn, "Understanding resistance: an analysis of Discourses in academic staff development", Studies in Higher Education, 37:1, 69-83, Routledge, Taylor \& Francis Group, South Africa, 2012.

[12] Illeris Knud, "Transformative Learning in Higher Education", Journal of Transformative Learning, Vol. 3 (1), 46-51, USA, 2015.

[13] Bonnie Amelia Dean, Michael Zanko, and Jan Turbill, "Mobilising PD: Professional development for sessional teachers through mobile technologies, Faculty of Business - Papers, University of Wollongong, Australia, 2015, pp.121.

[14] Australian Catholic University, "ACU Learning and Teaching Professional Development Website", Australia, 27 February 2017. http://www.acu.edu.au/867844

(Access Date: 1 March, 2017)

[15] Australian Catholic University, "Professional Development for Academic Staff Policy”, Australia, 19 December 2016. http://www.acu.edu.au/policy/170905

(Access Date: 1 March, 2017)

[16] Keith Trigwell and Susan Shale, "Student learning and the scholarship of university teaching", Studies in Higher Education, Vol. 29, No. 4, University of Oxford, UK, August 2004.

[17] Hui- Min Kuo, "Understanding relationships between academic staff and administrators: an organisational culture perspective", Journal of Higher Education Policy and Management, 31:1, 2009, pp. 43-54.

[18] Australian Catholic University, "The ACU Capability Development Framework with Guidance for Staff and Supervisors", ACU Human Resources Unit, Australia, August 2016. http://www.acu.edu.au/1099518

(Access Date: 1 March, 2017)

[19] Karen Smith, "Exploring the complex interplay of national learning and teaching policy and academic development practice", International Journal of Academic Development, Routledge, Taylor and Francis, UK, 2016, pp.1-10.

[20] Marie B. Fisher, \& Anna Gemmell, "Academic Teacher Induction in a Multiple Campus University Environment 1 -Opportunities for Change and Innovation", 2016, LICE 2016, London International Conference on Education Proceedings, pp. 95-99, Infonomics Society, 2016, London, UK. 